\title{
Delayed-Release Dimethyl Fumarate and Pregnancy: Preclinical Studies and Pregnancy Outcomes from Clinical Trials and Postmarketing Experience
}

\author{
Ralf Gold · J. Theodore Phillips · Eva Havrdova · Amit Bar-Or · Ludwig Kappos • \\ Norman Kim · Tim Thullen · Patricia Valencia · Lauren Oliva · Mark Novas · \\ Jie Li $\cdot$ Marianne T. Sweetser $\cdot$ Nuwan Kurukulasuriya $\cdot$ Vissia Viglietta $\cdot$ Robert J. Fox
}

To view enhanced content go to www.neurologytherapy-open.com

Received: August 3, 2015 / Published online: October 12, 2015

(C) The Author(s) 2015. This article is published with open access at Springerlink.com

\section{ABSTRACT}

Introduction: Delayed-release dimethyl fumarate (DMF; also known as gastro-resistant DMF) is an oral agent for the treatment of relapsing forms of multiple sclerosis (MS). No formal studies of DMF were conducted in pregnant women, although pregnancies have occurred during clinical trials and in the postmarketing setting.

Electronic supplementary material The online version of this article (doi:10.1007/s40120-015-0033-1) contains supplementary material, which is available to authorized users.

R. Gold ( $\square)$

St. Josef Hospital, Ruhr University, Bochum, Germany

e-mail: ralf.gold@ruhr-uni-bochum.de

J. T. Phillips

Multiple Sclerosis Program, Baylor Institute for Immunology Research, Dallas, TX, USA

E. Havrdova

Charles University, Prague, Czech Republic

A. Bar-Or

Montreal Neurological Institute and Hospital,

McGill University, Montreal, QC, Canada

L. Kappos

University Hospital, Basel Neurology, Basel,

Switzerland
Methods: Preclinical developmental and reproductive toxicology studies were performed with DMF in rats and rabbits. As of March 26, 2014, the DMF clinical development program included a total of 4132 subjects consisting of 2898 patients with MS, 320 psoriasis patients, 101 rheumatoid arthritis patients, and 813 healthy volunteers. Subjects were required to use reliable contraception and immediately discontinue treatment in the event of pregnancy.

Results: Animal studies showed no evidence of impaired fertility or teratogenicity with DMF. Overall as of June 30, 2014, 63 pregnancies were

N. Kim · T. Thullen · P. Valencia - L. Oliva ·

M. Novas · J. Li · M. T. Sweetser .

N. Kurukulasuriya $\cdot$ V. Viglietta

Biogen, Inc., Cambridge, MA, USA

Present Address:

M. T. Sweetser

Alnylam Pharmaceuticals, Inc., Cambridge, MA, USA

R. J. Fox

Mellen Center for Multiple Sclerosis Treatment and Research, Cleveland Clinic, Cleveland, $\mathrm{OH}, \mathrm{USA}$ 
reported in clinical trials. Outcomes are known for 39 of 42 subjects receiving DMF and include 26 live births (67\%), three spontaneous abortions (8\%), and 10 elective terminations (26\%); follow-up is ongoing in 2 cases and one patient was lost to follow-up. The incidence of spontaneous abortion in subjects exposed to DMF was consistent with the expected rate of early pregnancy loss in the general population (12-22\%). A total of 135 pregnancies were reported in the postmarketing setting (spontaneous and solicited reports). Outcomes are known for 30 cases and include 10 live births, 13 spontaneous abortions, and 5 elective terminations; follow-up is ongoing in 103 cases and 2 patients have been lost to follow-up.

Conclusion: Although data are limited and all known exposures have occurred in the first trimester, no increased risk of fetal abnormalities or adverse pregnancy outcomes associated with gestational exposure to DMF has been observed.

Funding: Biogen, Inc.

Keywords: Clinical trial; Delayed-release dimethyl fumarate; Multiple sclerosis; Postmarketing; Preclinical; Pregnancy; Safety; Women

\section{INTRODUCTION}

Multiple sclerosis (MS) is a leading cause of disability in young people and disproportionately affects women, with diagnosis often occurring during childbearing years [1]. Current practice generally advises women with MS who are planning to become pregnant to discontinue disease-modifying treatments (DMTs) before conception [2-4]. In cases of unintentional pregnancy, exposure to DMT is highly likely given the recent emphasis on early treatment and the approval of several small molecule oral therapies $[5,6]$. Yet, little is known about the safety of oral DMTs during pregnancy, and information is needed to assist patients and healthcare providers in weighing the benefits of remaining on DMT therapy to control disease activity versus the risk to the fetus from DMT exposure [2, 6].

Delayed-release dimethyl fumarate (DMF; also known as gastro-resistant DMF) is a novel oral agent for the treatment of relapsing forms of MS [7]. Although the mechanisms by which DMF exerts its therapeutic effects in MS are unknown, DMF and its metabolite, monomethyl fumarate (MMF), have been shown to activate the nuclear factor (erythroid-derived 2)-like 2 (Nrf2) pathway, which is involved in the cellular response to oxidative stress $[8,9]$. In MS clinical trials, DMF demonstrated efficacy on clinical and neuroradiological measures, including relapse rate, sustained disability progression, and lesion activity on magnetic resonance imaging over 2 years [10, 11]. Adverse events associated with DMF treatment include flushing; gastrointestinal events such as nausea, diarrhea, and abdominal pain; decreases in white blood cell and lymphocyte counts; and transient elevation in liver transaminases. Subjects treated with DMF did not have an increased risk of infection or malignancy.

Developmental and reproductive toxicology studies with DMF have been conducted in rats and rabbits. No formal studies of DMF in pregnant women have been conducted. Although recommendations to avoid pregnancy were in place for patients receiving DMF in clinical trials, a limited number of pregnancies occurred. This article provides data from the preclinical studies and long term retention as well as outcomes of pregnancies that occurred during the DMF clinical 
development program and in the postmarketing setting.

\section{METHODS}

\section{Preclinical Developmental and Reproductive Toxicology}

Developmental and reproductive toxicology studies were performed with DMF. International Conference on Harmonisation of Technical Requirements for Registration of Pharmaceuticals for Human Use (ICH) guidelines note that some minimal toxicity is expected to be induced at a sufficiently high dose [12]. Embryo-fetal development was evaluated in Sprague-Dawley rats $(n=25$ pregnant females per dose group) and New Zealand White rabbits $(n=20$ pregnant females per dose group). DMF aqueous suspension was administered by oral gavage to rats at doses of $0,25,100$, and $250 \mathrm{mg} / \mathrm{kg}$ and to rabbits at doses of $0,25,75$, and $150 \mathrm{mg} / \mathrm{kg}$ during the period of organogenesis (gestation days [GD] 7-18 in rats and GD 7-20 in rabbits). In both studies, maternal animals were observed for clinical signs, body weight, and food consumption, and subjected to laparohysterectomy. The fetuses were assessed for body weight, sex, and any alterations, including external, soft tissue, and skeletal changes. Fetal alterations were evaluated for malformation (permanent structural change that is likely to adversely affect the survival or health of the species) and variation (a change that occurs within the normal population under investigation and is unlikely to adversely affect survival or health) [13].

Pre- and postnatal development was assessed in Sprague-Dawley rats $(n=25$ pregnant females per dose group). These animals received DMF doses at $0,25,100$, and $250 \mathrm{mg} /$ $\mathrm{kg}$ by oral gavage for 35 days (GD 7 to lactation day 21). The offspring were assessed for post-weaning development, sexual maturation, and reproductive capacity by gross external examination. Neurobehavioral evaluation included passive avoidance test (learning, short-term and long-term retention) and water-filled M-maze test (overt coordination, swimming ability, learning, and memory), which were performed twice separated by 1 week.

Fertility was evaluated in male and female Sprague-Dawley rats. In the male fertility study, rats ( $n=25$ per dose group) received oral DMF doses of $0,75,250$, and $375 \mathrm{mg} / \mathrm{kg}$ for $>70$ days and through cohabitation with naive female rats. Mating and fertility performance, sperm evaluation, organ weights, gross necropsy, and histopathology of selected organs were assessed. In the female fertility study, rats $(n=25$ per dose group) received oral DMF doses of 0,25 , 100 , and $250 \mathrm{mg} / \mathrm{kg}$ for 21 days prior to cohabitation with naive male rats and for up to GD 7. Study assessments included estrous cycling, mating and fertility performance, and gross necropsy.

Juvenile toxicology studies in Sprague-Dawley rats were conducted that evaluated potential effects of DMF on growth, development, reproduction, and neurotoxicity. Male and female rats received oral DMF at 0, 5, $15,50,140$, and 375 (males only) $\mathrm{mg} / \mathrm{kg}$ from postnatal days (PND) 28 to 92 or 93 . Endpoints applicable to developmental and reproductive toxicology in these studies were neurobehavioral assessments (Functional Observation Battery, Startle Response, Motor Activity, and Learning and Memory/Biel Maze), reproductive function (estrous cycling, mating, 
parturition until PND 4, and spermatogenesis), and histopathological assessment (reproductive organs and neurological tissues).

\section{Clinical Trials and Postmarketing Experience}

No formal studies of DMF in pregnant women have been performed. The DMF clinical development program included healthy controls and patients with MS, with exposure to placebo, DMF, or glatiramer acetate (GA), which was the active comparator in one of the phase III trials [11].

In the DMF clinical development program, women who were pregnant, breastfeeding, or considering becoming pregnant during the course of the trial were excluded. Pregnancy was discouraged during the trials, and men and women of childbearing potential were required to use effective contraception during the study period. Urine pregnancy testing was conducted at regular intervals and study treatment was discontinued immediately in the event of pregnancy.

All pregnancies occurring during DMF clinical trials and their outcomes were included in this report. Pregnancy outcomes from the postmarketing setting were also included. The data cutoff date was June 30, 2014.

\section{Compliance with Ethics Guidelines}

All institutional and national guidelines for the care and use of laboratory animals were followed. All procedures followed were in accordance with the ethical standards of the responsible committee on human experimentation (institutional and national) and with the Helsinki Declaration of 1975, as revised in 2013. Informed consent was obtained from all patients for being included in the study.

\section{RESULTS}

\section{Preclinical Reproductive Toxicology}

There was no evidence of fetal teratogenicity (malformation) associated with DMF treatment in rats and rabbits. In female rats, reduced maternal body weight gain and maternal food consumption, satisfying the requirement to assess fetal toxicity in the context of some maternal toxicity according to regulatory guidelines [12], were accompanied by lower fetal weight and higher incidences of fetal variation (reduced ossification of the metatarsals and hindlimb phalanges) at the highest dose $(250 \mathrm{mg} / \mathrm{kg})$ compared to the control group (Table 1). The systemic exposure at $250 \mathrm{mg} / \mathrm{kg}$ is approximately 11-fold the human therapeutic dose based on area under the curve (AUC). The delay in skeletal ossification of forelimb and hindlimb phalanges has been shown to be dependent on low fetal body weight in rats $[14,15]$. With additional days of postnatal development, these bones would likely be fully ossified. These fetal effects were considered secondary to maternal toxicity from intolerability to the high-dose DMF suspension and were not expected to affect offspring growth or survival.

In rabbits, significantly reduced food consumption and corresponding low maternal body weight gain, satisfying the requirement to assess fetal toxicity in the context of some maternal toxicity according to ICH guidelines [12], led to increased abortion rate $(20 \% ; 4$ of 20 rabbits) at the highest dose $(150 \mathrm{mg} / \mathrm{kg})$, approximately equivalent to 16 times the human therapeutic dose of $480 \mathrm{mg} /$ day based 
Table 1 Maternal body weight changes, fetal body weight differences, and skeletal ossification variations in the embryo/fetal development study in rats

\begin{tabular}{llllll}
\hline $\begin{array}{l}\text { DMF } \\
(\mathbf{m g} / \mathbf{k g} / \text { day })\end{array}$ & $\begin{array}{l}\text { Mean maternal body } \\
\text { weight gain }(\mathbf{g}, \%)^{\mathbf{b}, \mathbf{c}}\end{array}$ & $\begin{array}{l}\text { Mean fetal body } \\
\text { weight }(\mathbf{g}, \%)^{\mathbf{c}}\end{array}$ & $\begin{array}{l}\text { Fetal skeletal variation: } \\
\text { number of bones with } \\
\text { ossification }\end{array}$ & $\begin{array}{l}\text { Exposure } \\
\text { margin }^{\mathbf{e}}\end{array}$ \\
\hline 0 & & & $\begin{array}{l}\text { Hindlimb } \\
\text { metatarsals }\end{array}$ & $\begin{array}{l}\text { Hindlimb } \\
\text { phalanges }\end{array}$ & \\
25 & 89.1 & 5.45 & 4.87 & 6.32 & - \\
100 & -1.8 & +1.7 & 4.85 & 6.46 & 1 -fold \\
250 & $-17.3^{* *}$ & +0.9 & 4.83 & 6.36 & 4 -fold \\
\hline
\end{tabular}

${ }^{*} P<0.05$ compared to mean control group value

${ }^{* *} P<0.01$ compared to mean control group value

${ }^{a}$ Delayed-release DMF (also known as gastro-resistant DMF); DMF dimethyl fumarate

b Body weight gain during the dosing period gestation days 7-17

${ }^{c}$ For controls, group mean is shown. For treated groups, percentage difference from control values are shown. Statistical significance is based on actual data (not on the percent difference)

d Mean number of bones with ossification per fetus per litter

${ }^{\mathrm{e}}$ Exposure margin ratios calculated based on human area under the curve exposure from United States Package Insert (USPI)

on AUC. Low food consumption has been shown to induce abortions in rabbits [16-19]. The four rabbits with abortions consumed the lowest amount of food $(<10 \mathrm{~g}$ /day on most days) during the treatment.

Maternal reductions in body weight gain were seen with high-dose DMF in the pre- and postnatal rat developmental study. Offspring body weight was significantly reduced at the highest DMF dose, followed by significantly delayed sexual maturation in males (balanopreputial separation). DMF had no effects on learning or short- or long-term retention in memory in the passive avoidance water-maze tests. This was further supported by the reproductive evaluation in the juvenile toxicology study in rats in which there were also no effects on startle responsiveness, motor activity, learning and memory, and functional observational battery. In addition, reproduction, including mating, fertility, copulation, conception, gestation length, estrous cyclicity, the process of parturition, spermatogenesis (concentration, morphology, and motility), histopathology of reproductive and neurological organs, and the growth, survival, and clinical condition of their pups (up to PND 4) were also unaffected.

There was no evidence that DMF impaired fertility in male or female rats. In males, minimal or mild interstitial (Leydig) cell hyperplasia in the testis was observed with all doses but had no effect on fertility. Pharmaceutical and non-pharmaceutical agents that cause Leydig cell changes in rats are common and have a low human relevance [20-22]. The number of non-motile sperm was slightly higher in the $375-\mathrm{mg} / \mathrm{kg}$ group compared to the control group; this finding was not statistically significant and considered 
inconsequential based on a normal number of motile sperm and lack of effect on fertility. In females, reductions in body weight gain and food consumption and disruption of estrous cycling (prolonged diestrous stage) in 5 of 25 rats were observed at the highest dose $(250 \mathrm{mg}$ / $\mathrm{kg}$ ) of DMF but without consequent effect on fertility.

\section{Pregnancy Outcomes in Clinical Trials}

As of March 26, 2014, the DMF clinical development program included 2898 patients with MS, 320 patients with psoriasis, 101 patients with rheumatoid arthritis, and 813 healthy volunteers, who were exposed to placebo, DMF, or GA. As of June 30, 2014, a total of 63 pregnancies were reported in clinical studies, including 42 in subjects exposed to DMF, 13 in subjects exposed to placebo, 4 in subjects exposed to GA, 1 in a patient who received blinded therapy, and 3 in subjects whom had discontinued DMF for more than 60 days at the time of their last menstrual period (LMP; Table 2). Outcomes are known for 39 of 42 pregnancies in subjects exposed to DMF, all 13 pregnancies in subjects exposed to placebo, 3 of 4 pregnancies in subjects exposed to GA, and one of three pregnancies where DMF was discontinued for more than 60 days at the time of their LMP.

The proportion of pregnancies with known outcomes that resulted in live births was similar in subjects exposed to DMF ( $n=26 / 39 ; 67 \%$ ) or placebo $(9 / 13 ; 69 \%)$. Of the 26 live births in subjects exposed to DMF, 22 were full-term ( $\geq 37$ weeks gestation), 2 were premature (33-36 weeks gestation), and in 2 cases the gestational age at birth was unknown. In most cases, the gestational age at last dose of DMF was 3-5 weeks. Of the 3 subjects whom had discontinued DMF for more than 60 days at the time of their LMP, 1 pregnancy resulted in a premature (35 weeks) live birth.

Table 2 Pregnancy outcomes from clinical trials as of June 30, 2014

\begin{tabular}{|c|c|c|c|c|c|c|}
\hline Pregnancy outcome & Placebo & $\mathrm{DMF}^{\mathrm{a}}$ & $\begin{array}{l}\text { Glatiramer } \\
\text { acetate }\end{array}$ & $\begin{array}{l}\text { Blinded } \\
\text { therapy }\end{array}$ & $\begin{array}{l}\text { Discontinued } \\
\text { DMF }^{\mathbf{b}}\end{array}$ & Total \\
\hline $\begin{array}{l}\text { Total number of women who became } \\
\text { pregnant }\end{array}$ & 13 & $42^{c}$ & 4 & 1 & 3 & 63 \\
\hline Live birth & 9 & 26 & 1 & 0 & 1 & 37 \\
\hline Spontaneous abortion & 2 & $3^{\mathrm{d}}$ & 0 & 0 & 0 & 5 \\
\hline Elective termination & 2 & $10^{\mathrm{e}}$ & 2 & 0 & 0 & 14 \\
\hline Pregnancy ongoing & 0 & 2 & 0 & 1 & 2 & 5 \\
\hline Lost to follow-up & 0 & 1 & 1 & 0 & 0 & 2 \\
\hline
\end{tabular}

a Delayed-release DMF (also known as gastro-resistant DMF); DMF dimethyl fumarate

b Subjects had discontinued DMF for $>60$ days at the time of their last menstrual period

c Patients from the pregnancy registry are not included in this analysis

d One subject who had a spontaneous abortion at 11 weeks gestational age had discontinued DMF $240 \mathrm{mg}$ three times a day 4 months earlier and was taking interferon beta-1a until 6 weeks gestational age

e One elective termination was in the setting of abnormalities detected on ultrasound at least 1 month after the patient discontinued DMF 
Spontaneous abortions occurred in 3/39 pregnancies with known outcomes $(8 \%)$ in subjects exposed to DMF and in $2 / 13$ pregnancies with known outcomes (15\%) in placebo recipients. These spontaneous abortions occurred early during the first trimester (gestation $\leq 12$ weeks). One of the spontaneous abortions occurred at 11 weeks gestational age. The patient discontinued DMF and then received interferon beta- $1 \mathrm{a}$ as rescue therapy until an estimated gestational age of 6 weeks; DMF three times daily (TID) was discontinued 4 months prior to the spontaneous abortion. This event was considered by the investigator to be unrelated to DMF. Another spontaneous abortion occurred at 9 weeks gestational age in a subject exposed to DMF TID at the time of conception and was considered by the investigator to possibly be related to DMF treatment. This subject received her last dose of DMF TID within 30 days of her LMP. The third spontaneous abortion occurred at 10 weeks gestational age in a subject who discontinued DMF at 6 weeks gestation; the event was considered unrelated to treatment. Elective terminations were reported for 10/39 (26\%) pregnancies in subjects exposed to DMF twice daily and 2/13 (15\%) pregnancies in placebo recipients. One elective termination was due to the detection of triploidy by ultrasound. This patient discontinued DMF at least 1 month prior to her LMP. In the four subjects exposed to GA, one live birth and two elective terminations were reported; one patient was lost to follow-up.

\section{Postmarketing Experience}

As of June 30, 2014, 135 pregnancies were reported in the postmarketing setting with DMF. Of these, 104 were spontaneous reports and 31 were solicited reports (Table 3). Pregnancy is ongoing in 103 of these cases and two patients were lost to follow-up; 10 live births, 13 spontaneous abortions, and 5 elective terminations were reported. One case of elective termination with fetal defects occurred in a female patient of advanced maternal age (39 years) and with a previous history of two full-term births and one miscarriage. The fetal defects on ultrasound were suggestive of caudal regression (rudimentary single, fused, short lower extremity), which is not consistent with results from animal studies that showed fetal rat development ossification delay related to decreased maternal nutritional status at a DMF dose approximately 11 times the human therapeutic dose. Of note, the patient had discontinued DMF 4 weeks after her last LMP, 2 weeks after conception. Development of the caudal region starts on GD 23-25, and given the short half-life of DMF, it is unlikely that DMF was present in the patient's system to impact the developing cauda of the fetus [23, 24]. Additional investigation of this case is ongoing to determine folic acid and diabetes status as potential confounding factors in fetal defects.

\section{DISCUSSION}

Relapsing MS afflicts more females, with an incidence at least threefold higher than that in males, and is typically diagnosed between the ages of 20 and 40 years [1]. Hence, there is a need for effective MS treatments that are safe for use in women of childbearing age. In the absence of formal studies in pregnant women, information on the safety of MS disease-modifying therapies during pregnancy comes from preclinical studies in nonhuman animals, outcomes of pregnancies occurring during clinical trials, and postmarketing 
Table 3 Pregnancy outcomes in the postmarketing setting as of June 30, 2014

\begin{tabular}{|c|c|c|c|}
\hline Pregnancy outcome & DMF $^{a}$ (spontaneous reports ${ }^{b}$ ) & DMF $^{a}$ (solicited reports ${ }^{c}$ ) & Total \\
\hline Total number of women who became pregnant & 104 & 31 & 135 \\
\hline Live birth & 5 & 5 & 10 \\
\hline Spontaneous abortion & 11 & 2 & 13 \\
\hline Ectopic pregnancy & 0 & 2 & 2 \\
\hline Elective termination & 4 & $1^{\mathrm{d}}$ & 5 \\
\hline Pregnancy ongoing & 83 & 20 & 103 \\
\hline Lost to follow-up & 1 & 1 & 2 \\
\hline \multicolumn{4}{|c|}{$\begin{array}{l}\text { a Delayed-release DMF (also known as gastro-resistant DMF); DMF dimethyl fumarate } \\
\text { b Spontaneous postmarketing reports } \\
\text { c Solicited postmarketing reports from Tecfidera Monitored Therapy Program } \\
\text { d There was one case of elective termination with fetal defects in a female patient of advanced maternal age ( } 39 \text { years) and } \\
\text { with a previous history of two full-term births and one miscarriage. The fetal defects on ultrasound were suggestive of caudal } \\
\text { regression (rudimentary single, fused, short lower extremity), which is not consistent with results from animal studies that } \\
\text { showed fetal rat limb development ossification delay related to decreased maternal nutritional status at a DMF dose } \\
\text { approximately } 11 \text { times the human therapeutic dose. Of note, the patient had stopped taking DMF } 2 \text { weeks after becoming } \\
\text { pregnant, which is prior to the development of the caudal region in humans (gestation days 23-25) [20] }\end{array}$} \\
\hline
\end{tabular}

pregnancy registries. This publication provides information regarding the safety of DMF in pregnancy.

In preclinical studies, there was no evidence of fetal malformations associated with administration of DMF. Fetal variations were observed only at maternally toxic doses of DMF and included lower fetal weight and reduced ossification. Maternal reductions in body weight and weight gain were seen with high-dose DMF in the pre- and postnatal rat study. Offspring body weight was significantly reduced at the highest DMF dose, followed by delayed sexual maturation in males only. There were no effects observed in neurobehavior in rats. In addition, there was no evidence that DMF impaired fertility in male or female rats. DMF received a pregnancy category $\mathrm{C}$ rating from the US Food and Drug Administration [7]. This classification is based on the lack of adequate and well-controlled studies in pregnant women and because of the fetal variations on growth and sexual maturation observed in animals. Pregnancy category C indicates that DMF should be used during pregnancy only if there is a clear need for MS treatment and the potential benefit justifies the potential risk to the fetus. Reports of data on exposure to MS therapeutics in pregnant women are the best available evidence on the effects of the drug in pregnancy because controlled studies are not conducted in pregnant women.

In the DMF clinical development program, 42 pregnancies occurred in patients exposed to DMF. While data are limited, there is currently no evidence of an increased risk of fetal abnormalities or adverse pregnancy outcomes associated with exposure to DMF during the first trimester. The proportion of pregnancies resulting in live births was similar in subjects exposed to DMF compared with those receiving 
placebo, and the incidence of spontaneous abortion was consistent with the expected rate of early pregnancy loss in the general population (12-22\%) [25]. Outcome is not yet known for four additional pregnancies from the clinical studies and for the majority of cases reported in the postmarketing setting. In addition, an observational patient registry (ClinicalTrials.gov identifier, NCT01911767) has been established to prospectively evaluate pregnancy outcomes in women with MS who are exposed to DMF at any time during pregnancy. Approximately, 310-375 pregnant women exposed to DMF will be enrolled to observe 300 prospective pregnancy outcomes. Fetal outcomes will be monitored for spontaneous abortions, birth defects, and other pregnancy and infant outcomes during pregnancy and for up to 12 weeks after delivery.

Until recently, therapies for MS were recombinant proteins that required parenteral administration $[2,5]$. The approval of oral agents may increase compliance and the incidence of unintentional pregnancy during therapy [2]. Of currently available oral therapies for MS, fingolimod is classified pregnancy category $\mathrm{C}$ and teriflunomide is classified pregnancy category $\mathrm{X}$, thus contraindicated in pregnancy due to the potential for fetal harm $[26,27]$. Outcomes data for 66 pregnancies with exposure to fingolimod were reported and showed evidence of abnormal fetal development in 5 cases [28]. Although the sample size is small, these data are consistent with animal studies and the product labeling indicating that women of childbearing potential should be advised to take effective contraceptive measures during fingolimod therapy $[26,28]$.

Interferon-beta has been associated with decreased mean birth weight and preterm delivery in some studies, but not low birth weight $(<2500 \mathrm{~g}), \quad$ cesarean delivery, spontaneous abortion, or congenital anomaly; however, evidence is conflicting [29-33]. Information on birth weight and delivery (vaginal versus cesarean) was not gathered during the DMF clinical development program; thus, the available data do not allow assessment of the effect of DMF on birth weight or delivery. Also, the majority of data in this report originates from subjects enrolled in clinical trials and may not be representative of the general population of people with MS.

\section{CONCLUSIONS}

Animal studies showed no evidence of teratogenicity or impaired fertility with exposure to DMF at doses that caused maternal effects. Although data are limited, there is no evidence to date of an increased risk of fetal abnormalities or adverse pregnancy outcomes associated with gestational exposure to DMF during the first trimester. Additionally, the incidence of spontaneous abortion was consistent with that reported in the general population. However, while the limited data here does not indicate an increased risk, there are no adequate and well-controlled studies among pregnant women exposed to DMF. In animals, adverse effects on offspring survival, growth, sexual maturation, and neurobehavioral function were observed when DMF was administered during pregnancy and lactation at clinically relevant doses. Therefore, as a pregnancy category $\mathrm{C}$ drug, regulators advise that DMF should be used during pregnancy only if the potential benefit justifies the potential risk to the fetus. A pregnancy registry has been established to monitor pregnancy outcomes in subjects receiving DMF. 


\section{ACKNOWLEDGMENTS}

This study and the article processing charges for this publication were funded by Biogen, Inc. The authors would like to acknowledge Janet Clarke, PhD (formerly of Biogen) for contributing to the preclinical toxicology study designs and interpretation of the data. Karyn M. Myers, PhD, of Biogen and Michelle McDermott, PharmD, provided writing support based on input from authors. Biogen reviewed and provided feedback on the paper to the authors. The authors had full editorial control of the paper and provided their final approval of all content. All named authors meet the International Committee of Medical Journal Editors (ICMJE) criteria for authorship for this manuscript, take responsibility for the integrity of the work as a whole, and have given final approval for the version to be published.

Disclosures. Ralf Gold has received honoraria from Bayer HealthCare, Biogen, Merck Serono, Novartis, and Teva Neuroscience; research support from Bayer HealthCare, Biogen, Merck Serono, Novartis, and Teva Neuroscience; and compensation from Sage for serving as editor of Therapeutic Advances in Neurological Disorders. J. Theodore Phillips has received consulting or speaking honoraria from Acorda, Biogen, Genzyme, Sanofi, and Xenoport, and research grant funding from Roche and Biogen. Eva Havrdova has received honoraria from Bayer, Biogen, Genzyme, GlaxoSmithKline, Merck Serono, Novartis, Sanofi, and Teva; research support from Biogen; and support by research project of Czech Ministry of Education PRVOUK-P26/LF1/4. Amit Bar-Or has received honoraria and/or research support from Amplimmune, Aventis, Bayhill Therapeutics,
Berlex, Biogen, Diogenix, Eli-Lilly, EMD Serono, Genentech, GlaxoSmithKline, Medimmune, Novartis, Ono Pharma, Receptos, Roche, Sanofi Genzyme, and Teva Neuroscience. Ludwig Kappos has received research support from Actelion, Allozyne, BaroFold, Bayer HealthCare, Bayer Schering, Bayhill Therapeutics, Biogen, Boehringer Ingelheim, Eisai, Elan, European Union, Genmab, Genzyme, GlaxoSmithKline, Glenmark, MediciNova, Merck Serono, Mitsubishi, Novartis, Novartis Research Foundation, Roche, Roche Research Foundation, Sanofi-Aventis, Santhera, Swiss MS Society, Swiss National Research Foundation, and Teva Neuroscience. Huixing Yuan, Patricia Valencia, Lauren Oliva, Mark Novas, Jie Li, Nuwan Kurukulasuriya, Norman Kim, Tim Thullen, and Vissia Viglietta are employees of and own stock/stock options in Biogen, Inc. Marianne T. Sweetser is an employee of Alnylam Pharmaceuticals, Inc. and was formerly employed at Biogen, Inc. and owns stock in Biogen, Inc. Robert J. Fox has received consultant fees from Allozyne, Avanir, Biogen, Novartis, Questcor, Teva, and Xenoport; served on advisory committees for Biogen and Novartis; research grant funding from Novartis.

Compliance with ethics guidelines. All institutional and national guidelines for the care and use of laboratory animals were followed. All procedures followed were in accordance with the ethical standards of the responsible committee on human experimentation (institutional and national) and with the Helsinki Declaration of 1964, as revised in 2013. Informed consent was obtained from all patients for being included in the study. 
Open Access. This article is distributed under the terms of the Creative Commons Attribution-NonCommercial 4.0 International License (http://creativecommons.org/licenses/ by-nc/4.0/), which permits any noncommercial use, distribution, and reproduction in any medium, provided you give appropriate credit to the original author(s) and the source, provide a link to the Creative Commons license, and indicate if changes were made.

\section{REFERENCES}

1. Tullman MJ. Overview of the epidemiology, diagnosis, and disease progression associated with multiple sclerosis. Am J Manag Care. 2013;19:S15-20.

2. Lu E, Wang BW, Synnes A, Dahlgren L, Sadovnick $\mathrm{AD}$, Tremlett $\mathrm{H}$. A review of safety-related pregnancy data surrounding the oral disease-modifying drugs for multiple sclerosis. CNS Drugs. 2014;28:89-94.

3. Lu E, Wang BW, Guimond C, et al. Safety of disease-modifying drugs for multiple sclerosis in pregnancy: current challenges and future considerations for effective pharmacovigilance. Expert Rev Neurother. 2013;13(3):251-61.

4. Coyle PK, Christie S, Fodor P, et al. Multiple sclerosis gender issues: clinical practices of women neurologists. Mult Scler. 2004;10:582-8.

5. Langer-Gould AM. The pill times 2: what every woman with multiple sclerosis should know. Neurology. 2014;82:1-2.

6. Fragoso YD, Boggild M, Macias-Islas MA, et al. The effects of long-term exposure to disease-modifying drugs during pregnancy in multiple sclerosis. Clin Neurol Neurosurg. 2013;115:154-9.

7. Tecfidera (dimethyl fumarate) prescribing information. Cambridge: Biogen Inc.; 2013. http:// www.tecfidera.com/pdfs/full-prescribing-information. pdf. Accessed Oct 21, 2014.

8. Linker RA, Lee DH, Ryan S, et al. Fumaric acid esters exert neuroprotective effects in neuroinflammation via activation of the Nrf2 antioxidant pathway. Brain. 2011;134:678-92.
9. Scannevin RH, Chollate S, Jung MY, et al. Fumarates promote cytoprotection of central nervous system cells against oxidative stress via the nuclear factor (erythroid-derived 2)-like 2 pathway. J Pharmacol Exp Ther. 2012;341:274-84.

10. Gold R, Kappos L, Arnold DL, et al. Placebo-controlled phase 3 study of oral BG-12 for relapsing multiple sclerosis. $\mathrm{N}$ Engl $\mathrm{J}$ Med. 2012;367(12):1098-107.

11. Fox RJ, Miller DH, Phillips $\mathrm{T}$, et al. Placebo-controlled phase 3 study of oral BG-12 or glatiramer in multiple sclerosis. $\mathrm{N}$ Engl J Med. 2012;367(12):1087-97.

12. International Conference on Harmonisation [ICH] S5(R2) guideline: Detection of Toxicity to Reproduction for Medicinal Products \& Toxicity to Male Fertility, current Step 4 version. 2005.

13. Chahoud I, Buschmann J, Clark R, et al. Classification terms in developmental toxicology: need for harmonization. Report of the second workshop on the terminology in developmental toxicology. Reprod Toxicol. 1999;13(1):77-82.

14. Chahoud I, Paumgartten FJR. Relationships between fetal body weight of Wistar rats at term and the extent of skeletal ossification. Braz J Med Biol Res. 2005;38:565-75.

15. Carney EW, Kimmel CA. Interpretation of skeletal variations for human risk assessment: delayed ossification and wavy ribs. Birth Defects Res B Dev Reprod Toxicol. 2007;80(6):473-96.

16. Matsuzawa T, Nakata M, Goto I, Tsushima M. Dietary deprivation induces fetal loss and abortion in rabbits. Toxicology. 1981;22(3):255-9.

17. Clark RL, Antonello JM, Wenger JD, Deverle-Brooks K, Duchai DM. Selection of food allotment for New Zealand white rabbits in developmental toxicity studies. Fundam Appl Toxicol. 1991;17(3):584-92.

18. Matsuoka T, Mizoguchi Y, Serizawa K, Ishikura T, Mizuguchi H, Asano Y. Effects of stage and degree of restricted feeding on pregnancy outcome in rabbits. J Toxicol Sci. 2006;31(2):169-75.

19. Cappon GD, Fleeman TL, Chapin RE, Hurtt ME. Effects of feed restriction during organogenesis on embryo-fetal development in rabbit. $\mathrm{BDR}(\mathrm{B})$. 2006;74:424-30.

20. Prentice DE, Meikle AW. A review of drug-induced Leydig cell hyperplasia and neoplasia in the rat and some comparisons with man. Hum Exp Toxicol. 1995;14(7):562-72. 
21. Cook JC, Klinefelter GR, Hardisty JF, Sharpe RM, Foster PM. Rodent Leydig cell tumorigenesis: a review of the physiology, pathology, mechanisms, and relevance to humans. Crit Rev Toxicol. 1999;29(2):169-261.

22. Clegg ED, Cook JC, Chapin RE, Foster PM, Daston GP. Leydig cell hyperplasia and adenoma formation: mechanisms and relevance to humans. Reprod Toxicol. 1997;11(1):107-21.

23. Zaw W, Stone DG. Caudal regression syndrome in twin pregnancy with type II diabetes. J Perinatol. 2002;22(2):171-4.

24. Litjens $\mathrm{NH}$, van Strijen E, van Gulpen C, et al. In vitro pharmacokinetics of anti-psoriatic fumaric acid esters. BMC Pharmacol. 2004;4:22. doi:10. 1186/1471-2210-4-22.

25. García-Enguídanos A, Calle ME, Valero J, Luna S, Domínguez-Rojas V. Risk factors in miscarriage: a review. Eur J Obstet Gynecol Reprod Biol. 2002;102(2):111-9.

26. Gilenya (fingolimod) prescribing information. East Hanover: Novartis International AG; 2014. http:// www.pharma.us.novartis.com/product/pi/pdf/ gilenya.pdf. Accessed Oct 21, 2014.

27. Aubagio (teriflunomide) prescribing information. Cambridge: Genzyme Corporation, a Sanofi company; 2012. http://products.sanofi.us/aubagio/ aubagio.pdf. Accessed Oct 21, 2014.

28. Karlsson G, Francis G, Koren G, et al. Pregnancy outcomes in the clinical development program of fingolimod in multiple sclerosis. Neurology. 2014;82:674-80.

29. Weber-Schoendorfer C, Schaefer C. Multiple sclerosis, immunomodulators, and pregnancy outcome: a prospective observational study. Mult Scler. 2009;15:1037-42.

30. Amato MP, Portaccio E, Ghezzi A, et al. Pregnancy and fetal outcomes after interferon- $\beta$ exposure in multiple sclerosis. Neurology. 2010;75:1794-802.

31. Houtchens MK, Kolb CM. Multiple sclerosis and pregnancy: therapeutic considerations. J Neurol. 2013;260:1202-14.

32. Dahl J, Myhr KM, Daltveit AK, Gilhus NE. Pregnancy, delivery and birth outcome in different stages of maternal multiple sclerosis. J Neurol. 2008;255(6):623-7.

33. Lu E, Wang BW, Guimond C, Synnes A, Sadovnick $D$, Tremlett H. Disease-modifying drugs for multiple sclerosis in pregnancy: a systematic review. Neurology. 2012;79(11):1130-5. 